La juventud argentina durante la Segunda Guerra Mundial. Una mirada desde periódicos nacionalistas

Laura Monacci

páginas / año 10 - n 22 Enero - Abril / ISSN 1851-992X/ pp.110-127/ 2018

http://revistapaginas.unr.edu.ar/index.php/RevPaginas

\title{
La juventud argentina durante la Segunda Guerra Mundial. Una mirada desde periódicos nacionalistas
}

\author{
Argentine Youth During the Second World War. A Look From \\ Nationalist Newspapers
}

\author{
Laura Monacci \\ Universidad Nacional de La Plata, Argentina \\ lauramonacci@gmail.com
}

\begin{abstract}
Resumen
La Segunda Guerra Mundial se caracterizó por ser un enfrentamiento en que primó el aspecto ideológico a la hora de conformar los bandos que se enfrentaron así como de construir al enemigo. Esto condujo a que adoptara características propias de choque en el plano internacional tanto como dentro de las fronteras de un mismo país afectando a la totalidad de la población, que se vio de una u otra manera involucrada, confrontando cuando no directamente en el frente de batalla- por la familia ideológica que defendían.

Argentina no estuvo exenta de dicho enfrentamiento ideológico, del que tomó partido gran parte de la sociedad y en que participó activamente un grupo que fue cobrando mayor visibilidad desde comienzos del siglo XX y a medida que la postura por un bando u otro se radicalizaba. Este grupo estaba compuesto por los jóvenes, que hacían sentir su voz en la arena política local, representando a sus movimientos y confrontando de igual a igual con sectores de la política anteriormente detentados exclusivamente por sus mayores.

Este trabajo pretende brindar luz sobre este colectivo heterogéneo en un periodo en que la juventud no siempre fue interpretada como un actor social autónomo.
\end{abstract}

\section{Palabras clave}

Juventud argentina; Segunda Guerra Mundial; nacionalismo; filo-fascismo; periódicos nacionalistas.

\begin{abstract}
The Second World War was a confrontation in which the ideological aspect prevailed when it came to shaping the sides that faced each other as well as building the enemy. This led to build particular characteristics at the international level as well as within the borders of the same country affecting the entire population, which was in one way or another involved, confronting -whether or not on the battle front- for the ideological family defended.

Argentina was not exempt from this ideological confrontation, from which a large part of society took part and in which a group that was gaining more visibility since the beginning of the 20th century actively participated, as the position by one side or the other became radicalized. This group was made up of young people, who raised their voice in the local political arena representing their movements and confronting on an equal footing with sectors of politics formerly held exclusively by their elders.
\end{abstract}

Esta obra está sujeta a la Licencia Reconocimiento-NoComercial-CompartirIgual 4.0 Internacional de Creative Commons. http://creativecommons.org/licenses/by-nc-sa/4.0/

(cc) BY-NC-SA 


\section{Laura Monacci}

This work aims to shed light on this heterogeneous group in a period when Youth was not always interpreted as an autonomous social actor.

\section{Keywords}

Argentine Youth; Second World War; Nationalism; Filo-fascism; Nationalist Newspapers

\section{Introducción: los jóvenes y el escenario global}

$\mathrm{Si}$ queremos analizar el fenómeno de la Juventud en el siglo XX, encontraremos que la mayoría de estudios sobre este colectivo se centran durante la segunda posguerra, reconociéndolo recién entonces como un actor social autónomo, emergente al calor de las transformaciones socioculturales de la época. En este nuevo contexto, los cambios por los que atravesaron "los jóvenes de las modernas sociedades postindustriales"1 estarían ligados al surgimiento del Estado de Bienestar; la crisis de la autoridad patriarcal; el nacimiento de un mercado de consumo específicamente juvenil; la internacionalización de la cultura juvenil ligada a los mass media; la erosión de una moral puritana, sustituida por una moral consumista $^{2}$. Estos cambios conducirían a su vez, según Eric Hobsbawm, a un ultra subjetivismo producto de la búsqueda por la realización del deseo individual -que impregnaría la lucha juvenil de este período- convirtiéndolo en su principal motor. A través de slogans del tipo "Cuando pienso en la revolución, me entran ganas de hacer el amor", se ponía dentro de un mismo plano la liberación personal y la liberación social, como mismos móviles del accionar político 3 .

Este autor, como Sergio Pujol -para el caso argentino- analiza a la juventud desde una perspectiva cultural-antropológica. Sería durante este periodo de "revolución social" y "revolución cultural" que los adolescentes se habrían transformado en un actor social consciente, reconocido gustosamente por los fabricantes de bienes de consumo y no tan entusiastamente por sus mayores, con quienes se sentirían cada vez menos identificados, ahondando la brecha intergeneracional ${ }^{4}$. Asimismo, para Pujol la existencia de este colectivo fuerte y nuevo estaría ligada a la apropiación simbólica y material de bienes culturales, construyéndose como un heterogéneo sujeto de consumo ${ }^{5}$.

Sin embargo, al poner el énfasis en la autonomía lograda por los jóvenes de la nueva sociedad de consumo y su masiva participación en los movimientos estudiantiles de la segunda posguerra, corremos el riesgo de no ver el rol distintivo jugado por la juventud en un periodo previo, impregnado por otras luchas relacionadas con el enfrentamiento ideológico propio de la época.

${ }^{1}$ Carles Feixa. De jóvenes, bandas y tribus. Antropología de la juventud. Barcelona, ed. Ariel, 1998, pp. 41-46.

2Ibídem, pp. 43.

${ }^{3}$ Eric Hobsbawm. Historia del siglo XX. Buenos Aires, Crítica, 2003. pp. 290-345.

${ }^{4}$ Ibídem.

${ }^{5}$ Sergio Pujol. La década rebelde. Buenos Aires, ed. Emecé, 2002, p. 76. 


\section{La juventud argentina durante la Segunda Guerra Mundial. Una mirada desde periódicos nacionalistas}

Nos resultan más enriquecedoras las lecturas que analizan a los jóvenes como un actor social autónomo producto de procesos previos, más extensos, que rastrean sus orígenes en el surgimiento y las transformaciones de la sociedad capitalista, obteniendo hacia fines del siglo XIX un rol diferenciado y reconocido dentro de sus sociedades. Para Philippe Ariès, ya hacia el 1900 surgen interrogantes sobre "qué pensarán los jóvenes", y comienzan a publicarse investigaciones al respecto: "La juventud aparece como detentora de valores nuevos susceptibles de vivificar la anticuada y estancada sociedad"6. Siguiendo la misma línea, Carles Feixa, tomando como referente a John Gillis, agrega que el concepto que el autor denomina "era de la adolescencia" se había limitado hasta entonces a los varones de la burguesía. Recién a comienzos de siglo XX este concepto se democratiza extendiéndose a otros colectivos como las mujeres, los obreros, los jóvenes de las zonas rurales y de los países no occidentales ${ }^{7}$. En el mismo sentido, Sandra Souto Kustrin retoma esta línea, pero atendiendo a las particularidades de cada grupo de jóvenes en cada época y región:

Los jóvenes por consideraciones de edad no han formado nunca un todo homogéneo sino que han reflejado las divisiones económicas, sociales y políticas existentes en la sociedad. Además, el fenómeno que conocemos como modernización tuvo diferente ritmo y cronología en los distintos países. Todo esto hizo que el proceso de configuración de la juventud como grupo social tuviese también un ritmo distinto, no sólo en cada país, sino dentro de éstos, en el mundo urbano y en el rural, en las diferentes clases sociales y los géneros: la juventud surgió en primer lugar como un fenómeno urbano, masculino y de clases altas y medias 8 .

En el estudio histórico-cultural que realizan Carlos Reina Rodríguez y Fernanda Cortez Navarro se propone el estudio de "las juventudes" -en plural- ya que entienden que no hubo una sola en un periodo determinado -sino varias, conviviendo simultáneamente, con sus similitudes y contradicciones- y que ésto queda en manifiesto cuando se realiza un abordaje histórico de las mismas ${ }^{9}$.

En la perspectiva antropológica de Carles Feixa, la juventud aparece como una "construcción cultural", relacionada con una serie de condiciones sociales y de imágenes culturales que dependen a su vez del tejido estructural social en general, que engloba en sí las instituciones políticas, las relaciones entre los distintos grupos, las formas de subsistencia, y las cosmovisiones ideológicas, propias de cada

\footnotetext{
${ }^{6}$ Philippe Ariès. El niño y la vida familiar en el antiguo régimen. Madrid, Taurus, 1990, en Carles Feixa. De jóvenes, bandas y tribus..., Op. Cit, p. 36.

${ }^{7}$ Carles Feixa. De jóvenes, bandas y tribus..., Op. Cit, p. 39. Es necesario aclarar que las mujeres cobrarán mayor autonomía, independencia y visibilización durante la segunda mitad del siglo XX, en función de los cambios de la nueva época a que se hacía referencia anteriormente.

8Sandra Souto Kustrín. "Introducción: juventud e historia". Hispania. Revista española de Historia. Vol. LXVII, № 225, Madrid, enero-abril 2007, p. 13.

${ }^{9}$ Fernanda Cortés Navarro y Carlos Reina Rodríguez. Historia, juventudes y política: de la Escuela Republicana del siglo XIX a las élites y juventudes políticas en los gobiernos del siglo XX en Colombia. Bogotá, ed. UD, 2014, p. 27.
} 


\section{Laura Monacci}

sociedad. De esta manera existen para este autor cinco grandes modelos de juventud correspondientes a diferentes formas de organización social:

los 'púberes' de las sociedades primitivas sin Estado; los 'efebos' de los Estados antiguos; los 'mozos' de las sociedades campesinas preindustriales; los 'muchachos' de la primera industrialización; y los 'jóvenes' de las modernas sociedades postindustriales. No se trata de modelos unívocos, sino más bien de 'tipos ideales' que sirven para ordenar la heterogeneidad de los datos etnográficos e históricos. En cada caso deben combinarse con otras estratificaciones internas (como las geográficas, históricas, étnicas, sociales y de género ${ }^{10}$.

Siguiendo este esquema de larga duración, que consideramos pertinente para el análisis de los jóvenes que actuaron durante el periodo de entreguerras y la Segunda Guerra Mundial, en este trabajo nos encontramos con "los muchachos de la primera industrialización”. Estos jóvenes fueron parte y producto de la experiencia surgida tras el largo proceso de transición del feudalismo al capitalismo, periodo en que se dio forma a ciertas instituciones emblemáticas -dentro del nuevo contexto de la Modernidad-, definitorias de las principales características de estos grupos. Las instituciones arquetípicas a las cuales se hace referencia fueron la nueva familia burguesa; el trabajo, en el contexto de las nuevas relaciones de producción capitalista; la escuela y el ejército, como instituciones fundantes de la identidad nacional extendida -en el marco de los nuevos estados surgidos al calor de las transformaciones que trajo consigo la Revolución francesa- encargadas de formar a los nuevos ciudadanos que habitaban dentro de sus fronteras ${ }^{11}$.

Hacia fines del siglo XIX, con el desarrollo urbano e industrial y la mundialización de la economía, tuvo lugar un avance democrático que permitió a las masas una mayor participación en la arena política, generando movimientos radicalizados desde la nueva derecha nacionalista antisemita y desde la izquierda, a partir del creciente movimiento obrero, y que encontraron mayores vías de difusión gracias a las nuevas y mejores vías de comunicación a nivel global ${ }^{12}$. Con el estallido de la Primera Guerra Mundial se inauguró una nueva forma de enfrentamiento caracterizada por el esfuerzo de guerra total, que requería aplicar todos los recursos humanos y materiales al esfuerzo bélico, dando lugar a lo que Furet denominó "guerra industrial" y "guerra democrática"13. Esto implicó una nueva y mayor participación de las masas en el conflicto, involucrándolas no solo como protagonistas en el frente de batalla, sino como la mano de obra que sostenía y reproducía el desarrollo material de la guerra. El involucramiento desde todos estos ámbitos y el sacrificio realizado por la sociedad civil condujo a un punto sin retorno

\footnotetext{
${ }^{10}$ Carles Feixa. De jóvenes, bandas y tribus..., Op. Cit, pp. 18-19.

${ }^{11}$ Ídem, p. 36. Para mayores referencias al rol de estas instituciones durante el surgimiento del Estado-Nación ver: Josep Fontana. Introducción al estudio de la historia. Barcelona, Crítica, 1999. ${ }^{12} \mathrm{Ma}$. Dolores Béjar. Historia del siglo XX; Europa, América, África y Oceanía. Buenos Aires, Siglo XXI, 2011.

${ }^{13}$ François Furet. El pasado de una ilusión, Ensayo sobre la idea comunista en el siglo XX. Madrid, FCE, 1996.
} 


\section{La juventud argentina durante la Segunda Guerra Mundial. Una mirada desde periódicos nacionalistas}

en que el pueblo se sintió con derecho a reclamar su activa participación en la toma de decisiones políticas. La Revolución rusa y los levantamientos de posguerra vinieron a dar cuenta de lo que las masas eran capaces de provocar al ser desoídas.

Para los jóvenes, la participación en la guerra significó una liberación de la opresión familiar y de la jerarquía patriarcal, que los convirtió, a su vez, en protagonistas de la historia en tanto artífices del devenir colectivo por su rol en el campo de batalla o en los estallidos revolucionarios que se suscitaron durante y después del conflicto. Sus reclamos comenzaron a cobrar mayor visibilidad como consecuencia de una mayor organización de las bases y mediante la planificación sociocultural de los nuevos gobiernos emergentes en la primera posguerra. Según Sandra Souto Kustrín:

Fue en el periodo comprendido entre las dos guerras llamadas mundiales cuando los jóvenes se convirtieron en un problema social y político, pero también fueron considerados el origen del futuro, los transformadores de la sociedad, como no lo habían sido antes ${ }^{14}$.

A lo largo de los 21 años que transcurrieron entre la finalización de la Primera y el comienzo de la Segunda Guerra Mundial podía observarse que la forma que adoptaría un nuevo enfrentamiento no sería entre estados, como lo había sido durante la Gran Guerra, sino que se desarrollaría como una guerra civil nacional e internacional que implicaría a dos familias ideológicas en el conflicto: "por un lado los herederos de la Ilustración del siglo XVIII y de las grandes revoluciones, incluida, naturalmente, la revolución rusa; por el otro, sus oponentes" y se disputaría tanto internacionalmente como hacia el interior de las fronteras de los estados nacionales, que vieron en sus sociedades una creciente toma de partido por uno u otro campo ${ }^{15}$.

Esta nueva forma de enfrentamiento implicó una mayor radicalización de la violencia -tanto explícita como discursiva- ejecutada por las nuevas y múltiples agrupaciones que, a uno y otro lado del Atlántico, componían el abanico ideológico que iba de la extrema derecha a la extrema izquierda.

A lo largo de estos años de enfrentamiento, y a medida que éste se recrudecía, fue cobrando mayor visibilidad un nuevo colectivo político conformado por jóvenes, que participaban activamente en los diversos bandos que componían las nuevas familias ideológicas, y que se diferenciaban de sus pares y de otros grupos etarios tanto por su accionar como por su organización programática. Argentina no sólo no estuvo exenta de este conflicto, sino que hacia el interior de sus fronteras cobró unas dimensiones inusitadas, atravesadas por el desarrollo de sus problemáticas locales particulares que adquirían a su vez un nuevo cariz de la mano del gran flujo de inmigrantes provenientes de Europa, que desde finales del siglo XIX complejizaban el escenario ideológico nacional.

\footnotetext{
${ }^{14}$ Sandra Souto Kustrín. “Introducción: juventud e historia”..., Op. Cit, p. 14.

${ }^{15}$ Eric Hobsbawm. Historia del siglo XX..., Op. Cit, p. 150.
} 


\section{Laura Monacci}

Una de las primeras instituciones en ver la potencialidad movilizadora de la juventud fue la Iglesia Católica, que encauzó hacia sus filas ingentes masas de jóvenes a partir de la creación de las Juventudes Católicas u otros movimientos afines especializados, como la Juventud Obrera Cristiana ${ }^{16}$. Asimismo, tanto en los partidos fascistas como en el programa de los bolcheviques en la URSS, los jóvenes ocuparon un lugar central, distinguido de otros grupos, a la hora de pensarlos como un actor político autónomo dentro de estos movimientos ${ }^{17}$.

En la URSS, la creación de la "personalidad colectiva" a la que apuntaba el partido exigía una nueva "estructura del alma"18. A diferencia de la lectura de los jóvenes occidentales de la segunda posguerra que hace Hobsbawm ${ }^{19}$-entre otroscomo sujetos individualistas y subjetivistas, lo personal ligado a lo político estaba entonces plenamente relacionado con el desarrollo del sujeto colectivo soviético, no con un deseo de realización subjetivo. La educación soviética era pensada como un arma fundamental para llevar a cabo estos fines. A los niños y niñas soviéticos se los enrolaba a los diez años en los Pioneros, una organización en la que se les inculcaba el valor por el trabajo y la disciplina comunista, haciéndolos experimentar un intenso sentimiento de pertenencia e inclusión social. A los quince años alrededor de 1/5 de estos jóvenes pasaban a formar parte del Komsomol, otra organización bolchevique destinada a formar los próximos cuadros del partido.

Pero especialmente fueron el fascismo y el nazismo los movimientos que explotaron de manera más eficaz el encuadramiento político de los jóvenes, encontrando Hitler en las Juventudes Hitlerianas y Mussolini en los Balilla y Avanguardisti italianos sus cuadros más activos y devotos. Es por esto que los Estados fascistas se interesaban particularmente por la juventud y por monopolizar la formación de los jóvenes, con el fin de moldear al hombre y a la mujer del futuro (cada uno, desde ya, en la esfera de participación que le correspondía), "que fuesen al mismo tiempo combatientes y súbditos dóciles"20. Estas medidas implicaban una reestructuración social y cultural de alto impacto, desarmando antiguas redes de pertenencia social e ideológica, que sólo podía lograrse mediante una "revolución del alma"21.

El nuevo protagonismo que fueron cobrando estos movimientos y en que se desarrolló la juventud de primera mitad del siglo XX conduce a Sandra Souto "a considerar este periodo como el de la primera 'gran oleada' de movilización juvenil

\footnotetext{
${ }^{16}$ Carles Feixa. De jóvenes, bandas y tribus..., Op. Cit, pp. 40-41.

${ }^{17}$ Vale aclarar que aunque tomemos particularmente estos dos regímenes y su relación con los jóvenes, no implica que los consideremos conjunta e indiferenciadamente, englobándolos dentro de una misma categoría analítica, como se plantea a partir del concepto de "totalitarismo". Para analizar las diferencias entre uno y otro sistema y ver los riesgos del uso del concepto "totalitarismo" ver: Ian Kershaw. "Nazisme et stalinisme. Limites d'une comparaison". Le Débat. Vol. II, N 89, París, marzo-abril 1996, pp. 177-189.

${ }^{18}$ Orlando Figes. Los que susurran. La represión en la Rusia de Stalin. Buenos Aires, Edhasa, 2009, p. 48.

${ }^{19}$ Eric Hobsbawm. Historia del siglo XX..., Op. Cit, pp. 322-345.

${ }^{20}$ Robert Paxton. Anatomía del fascismo. Barcelona, ed. Península, 2004, p. 168.

${ }^{21}$ Ibídem. p. 166.
} 


\section{La juventud argentina durante la Segunda Guerra Mundial. Una mirada desde periódicos nacionalistas}

en el mundo occidental, en contraposición a la valoración tradicional que destacaba la 'novedad' de los movimientos juveniles de los años sesenta del siglo XX"22 sobre la cual se hacía mención más arriba.

En este sentido, la búsqueda por diferenciarse de sus adultos sería un rasgo similar característico tanto de los jóvenes de la primera mitad del siglo XX como de los de las "sociedades posindustriales" de la segunda mitad, que los conduciría a la acción política en uno y otro momento, más allá de que las causas de su accionar proviniera de distintos móviles. Sin embargo, este aspecto no puede desviarnos del análisis de la particular coyuntura histórica que implicaba para estos jóvenes en cada caso asumir riesgos, tomar decisiones y actuar en función de una verdadera creencia en el programa político-ideológico por el cual, en muchos casos, se ponía la vida en juego. Un análisis basado exclusivamente en la rebeldía contra las jerarquías parentales relacionada con la edad nos impide ver el auténtico rol de sujetos políticos maduros que los jóvenes asumieron a lo largo del siglo XX, tanto durante la primera como durante la segunda mitad de la centuria. Consideramos que es fundamental historizar a la juventud, dando cuenta de sus particularidades específicas en cada periodo histórico con el fin de poder visibilizar la forma en que se interrelacionó con otros sectores de la sociedad y su accionar político, distinguiéndolos de los jóvenes de otras épocas.

En este trabajo nos centraremos específicamente en la juventud del periodo de entreguerras y de la Segunda Guerra Mundial, en particular. Nuestro objetivo consiste en observar el rol social y político cumplido por la juventud nacionalista, analizando la particular coyuntura histórica en Argentina y la forma en que este país se vinculó al escenario mundial, poniendo el foco sobre cómo los jóvenes tomaron las riendas de la acción directa, convirtiéndose en el brazo armado de sus agrupaciones, haciéndose eco y encarnando un proyecto colectivo. Esto los convirtió en un actor social activo, autónomo, que en Argentina se desarrolló en tensión con otros sectores afines y con sus homólogos en las antípodas ideológicas, en un periodo de altísima radicalización social y acción directa de diversas y numerosas agrupaciones, producto de las transformaciones locales, en diálogo con el complejo escenario internacional.

\section{Escenario argentino y diarios nacionalistas}

Hacia fines de la década de 1920, con la nueva elección de Yrigoyen, se instaló una percepción general en los sectores conservadores de que la crisis sociocultural empeoraba23. Esto estimuló el crecimiento de un nuevo nacionalismo derechista exacerbado, basado en los intelectuales europeos como Charles Maurras, José Ortega y Gasset, Ramiro de Maeztu. Estos nuevos nacionalistas "glorificaban el

\footnotetext{
${ }^{22}$ Sandra Souto Kustrín. “Introducción: juventud e historia”..., Op. Cit, p. 14.

${ }^{23} \mathrm{El} 1$ de abril de 1928 Hipólito Yrigoyen fue reelecto por más del 60\% de los votos para ejercer su segunda presidencia, en el contexto de una gran participación popular que involucró al $80 \%$ del electorado. Sin embargo su mandato no llegó a término, ya que el 6 de septiembre de 1930 fue depuesto por un golpe de Estado liderado por el general José Félix Uriburu.
} 


\section{Laura Monacci}

irracionalismo, el vitalismo y la juventud, y denunciaban de modo explícito a la democracia liberal tanto como a la izquierda radical"24.

A ojos vista de estos grupos, la creciente crisis era producto del escenario socio-político que había permitido el ingreso de las masas en la arena política a partir de la revolución rusa; en Argentina de la Ley Sáenz Peña de voto universal, y por causa de la creciente inmigración que había trastocado el normal devenir de la política y la cultura local. Tras el golpe de Estado de 1930, que llevó a José Félix Uriburu al poder, las organizaciones nacionalistas se multiplicaron. A lo largo de la que Daniel Lvovich llama "la larga década del nacionalismo", que abarca el período que transcurre entre 1932 y 1943, se produjo una expansión del movimiento nacionalista generando la transformación “de un pequeño grupo de intelectuales convertidos en conspiradores en un movimiento militante de protesta"25.

Desde las páginas de los diarios que nos ocupan, el temor a la infiltración de una amenaza foránea, de los grupos locales que la representan, así como el enaltecimiento de los jóvenes nacionalistas que defienden los verdaderos valores de la patria, son continuamente presentados como las dos caras de una misma moneda. En este trabajo tomamos como fuente, El Pampero y el diario que lo continuó tras su clausura en enero de 1944: El Federal: Soberanía o Muerte. Ambos estaban dirigidos por el ultranacionalista y antisemita Enrique Osés, quien además tuvo a su cargo en este período la dirección de otros diarios -La Maroma, Crisol-y a quien se lo vinculaba con la embajada alemana, no sólo por los fondos para sus periódicos -que ésta aportaba- sino como informante durante la Segunda Guerra. El Pampero salió a la luz el 1 de septiembre de 1939, y fue cerrado el 27 de enero de 1944, por motivo de fuertes críticas al gobierno de Ramírez y su decisión de romper relaciones con los países del Eje ${ }^{26}$.

El Federal surgió como continuación de El Pampero. Con motivo de una cena aniversario nacionalista, conmemorativa de los 5 años del surgimiento de El Pampero, fue publicado en El Federal un discurso pronunciado por Osés en esa ocasión. Bajo el título: "Surgimos para impedir la enajenación de una sola partícula de la soberanía”, explica que tras la caída del gobierno de Ramírez: "ya estaba de nuevo en las calles, el eco de aquel diario cuyo retorno en nombre no debía ser, pero cuya ausencia en espíritu tampoco podía ser" y más adelante prosigue: "al aparecer el diario El Federal dijimos que esto era la continuidad de El Pampero"27. Se siguió publicando hasta diciembre de 1944, al menos el del 7 de diciembre es el último

\footnotetext{
${ }^{24}$ Ronald Newton. El cuarto lado del triángulo. La "amenaza nazi" en la Argentina (1931-1947). Buenos Aires, Ed. Sudamericana, 1995, p. 167.

${ }^{25}$ Daniel Lvovich. Nacionalismo y antisemitismo en la Argentina. Buenos Aires, ediciones B Argentina S.A., 2003, p. 295.

${ }^{26}$ El 26 de enero de 1944 Argentina rompió relaciones diplomáticas con los países del Eje tras haberse descubierto una red secreta de espionaje del Tercer Reich operando en nuestro país. Este hecho, sumado a la continua presión estadounidense, precipitaron la ruptura que se dio a conocer mediante un decreto firmado por Pedro Pablo Ramírez, el presidente de facto que el levantamiento militar del 4 de junio 1943 había puesto en el poder.

27 “Surgimos para impedir la enajenación de una sola partícula de la soberanía”. El Federal, Bs. As., 4/11/1944, p. 3.
} 


\section{La juventud argentina durante la Segunda Guerra Mundial. Una mirada desde periódicos nacionalistas}

ejemplar con que contamos. Uno de los motivos posibles de por qué se siguió publicando hasta una fecha tan tardía puede haber sido algún permiso concedido a Osés tras el golpe que llevó a Farrell al poder, ya que desde estas páginas se brindaba un amplio y manifiesto apoyo a su gobierno.

A partir de su posicionamiento ideológico, se plasmaron aquí ideas en torno a qué políticas seguir durante y después de la guerra, presentando a su vez los potenciales riesgos que corría la tan valorada soberanía nacional en el devenir de la particular coyuntura mundial, poniendo el acento en la supuesta existencia y crecimiento de un enemigo externo, que complotaba en el interior del país con agentes locales que servían a sus fines, constituyéndose como una amenaza directa. Este imaginario se construía y alimentaba, entre otras cosas, de acuerdo al reflejo de las fluctuaciones de las potencias del Eje a lo largo de la guerra, su posicionamiento, avances y retrocesos.

Los fondos para estas publicaciones procedían de diversos orígenes. Desde Alemania, por medio de la División de Asuntos Externos del ProMi (Propagandaministerium o Ministerio de Propaganda) de Goebbels y la DNB (Deutsches Nachrichten Büro u Oficina de Noticias Alemana) que era la agencia oficial del ProMi. También estaba subordinada al Ministerio de Propaganda la organización Trans Ocean (T.0), que era la versión de ultramar de la empresa de noticias Europa Press, y de la cual se hace reiterada mención en nuestros diarios. El Pampero recibía directamente desde Berlín 42.000 marcos mensuales ${ }^{28}$. Pero también se financiaban mediante agencias alemanas locales o mediante entidades oficiales como YPF o el Banco de la Provincia de Buenos Aires ${ }^{29}$.

Si bien la embajada alemana contribuía, con los fondos que aportaba, al mantenimiento de estos diarios, y su política en el extranjero estaba orientada a desarrollar una intensa guerra de propaganda -especialmente contra sus principales rivales comerciales en Argentina: Estados Unidos e Inglaterra- no pueden desconocerse los genuinos motivos de identificación político-ideológica que movilizaban a diferentes sectores de la sociedad, en particular a sectores tan efervescentes como los jóvenes, que dieron forma a sus movimientos, en muchos casos constituyéndose, como decíamos anteriormente, en su brazo armado. La enorme participación filonazi en la celebración con motivo de la anexión de Austria por parte de Alemania (Anschluss) que se llevó a cabo en el estadio Luna Park el 10 de abril de 1938 -estimada entre 18.000 y 20.000 asistentes-, da cuenta de lo complejo y masivo de su organización ${ }^{30}$.

Una vez comenzada la Segunda Guerra Mundial, se produjo un endurecimiento en torno al posicionamiento ideológico y una mayor actitud defensiva por parte de la derecha nacionalista local ligada al temor que generaba la eventual influencia de ideas radicales, en el contexto de la guerra, tendientes a minar

\footnotetext{
${ }^{28}$ Daniel Muchnik. El rechazo mundial a los judíos. Buenos Aires, Ariel, 2014, pp. 68-70.

${ }^{29}$ Daniel Lvovich. Nacionalismo y antisemitismo..., Op. Cit, p. 325.

30 Ibídem, pp. 229-230.
} 


\section{Laura Monacci}

la soberanía nacional, considerada uno de los principales baluartes a ser defendidos, implicara lo que implicara. En este contexto, por su potencial explosivo y por su capacidad organizativa, la juventud fue vista como un actor social destacado, que podía representar y diseminar lo peor y lo mejor del escenario ideológico internacional.

Por un lado existían los grupos de jóvenes más vulnerables desde donde se podía infiltrar el enemigo externo, valiéndose de ellos como "títeres" por medio de los cuales ejercer sus verdaderas intenciones desestabilizantes. Así, los espacios educativos tanto como recreativos que funcionaban por fuera de la línea de la oficialidad institucional -especialmente tras el golpe del 4 de junio de 1943-fueron vistos con desconfianza, como espacios a ser temidos y condenables. En la siguiente cita vemos cómo los "espíritus incautos", inadvertidos, eran potenciales vías del "germen de disolución social":

"El centro de Estudios Libres de Bahía Blanca es un temible foco de irradiación comunista" 31 ... Desde ellos la idea roja era infiltrada en los espíritus incautos y el germen de disolución social se desparramaba a diestra y siniestra con una inconsciencia tremenda. Estudiantes secundarios, universitarios, con su título bajo el brazo, miembros conspicuos de colectividades extrañas, dirigentes del proletariado, liberales ingenuos, democráticos enceguecidos, formaban el auditorio de esas entidades culturales o de investigaciones (i) [sic] sociales... En definitiva, el veneno letal que destruye en los espíritus de los auditorios heterogéneos, ingenuos e incautos como los que asistían a esas asambleas, toda idea sana de redención nacional, toda tentativa de argentinización, todo propósito de liberación ${ }^{32}$.

Este párrafo condensa gran parte del esqueleto del pensamiento nacionalista. El enemigo -difuso en su demarcación, aunque enfática su adjetivaciónrepresentado por: "las colectividades extrañas"; el "proletariado"; los "liberales ingenuos"; "democráticos enceguecidos", poniendo en riesgo los valores más puros de "redención nacional"; "argentinización" y "todo propósito de liberación", que encarnarían los nacionalistas.

En este sentido el comunismo era visto como una de las peores y más temibles amenazas que, mediante los más viles ardides y engaños promulgaba la revolución, el internacionalismo y ateísmo, contaminando a sectores permeables, por su ingenuidad, desviándolos de las "sendas correctas" y subvirtiendo todos los valores nacionales. En este caso, otro de los espacios colonizado por los comunistas, desde donde corroían a la sociedad y a otros jóvenes, era la universidad. Esta institución aparece cuestionada continuamente desde estas páginas, como un reducto de la "antipatria" que actuaba prácticamente como un vórtice por donde se filtraban las ideas foráneas que atentaban contra la soberanía nacional:

\footnotetext{
${ }^{31}$ Los títulos en las citas subsiguientes aparecerán entrecomillados.

32"El centro de Estudios Libres de Bahía Blanca es un temible foco de irradiación comunista". El Pampero, Bs. As., 11/6/1943, p. 6.
} 


\section{La juventud argentina durante la Segunda Guerra Mundial. Una mirada desde periódicos nacionalistas}

"Los agitadores comunistas no cejan en su afán de confundir la conciencia del pueblo"... Los hipócritas de la FUA: Los grupos comunistas de la universidad adoptan una táctica de enmascaramiento y de hipocresía. Así es como utilizan a la F.U.A. para todas las gestiones oficiales, en tanto realizan su propaganda con el rótulo de "núcleo de estudiantes democráticos" 33 .

El mensaje, sin embargo, resulta contradictorio ya que por un lado representan un peligro frente al resto del estudiantado: "Estos federastas descalificados son los mismos que en lugar de preocuparse de estudiar, agitan al estudiantado con el cuento de la reforma universitaria" pero por otro lado son repudiados por éste: "amén de no poseer en ninguna forma la representación del estudiantado que los repudia, sirven de pantalla a los desdoblamientos comunistas de la Facultad"34.

El comunismo representaba además un enemigo que disputaba para sus filas los mismos sectores que pretendían sumar los nacionalistas: los jóvenes en general y los obreros (y los jóvenes obreros) en particular. En estos grupos las actividades de propaganda y contrapropaganda fueron especialmente intensas. Cuando se hace mención a "la pantalla comunista a la que sirven" desde las facultades, se está haciendo referencia a la capacidad de filtrar transversalmente distintos sectores de la sociedad, potencialmente permeables a la agitación comunista:

Cuando los comunistas se ven forzados a aceptar un hecho de fuerza que los perjudica acuden a un resorte: la organización de una huelga general de carácter netamente subversivo, a fin de desorganizar el poder del Estado. Presumiblemente la actividad comunista se dirija hoy a lograr esa finalidad, promoviendo agitación en los sindicatos y entidades obreras y estudiantiles de carácter gremial ${ }^{35}$.

Junto al temor comunista convivía otro de los grandes enemigos del nacionalismo argentino: la democracia liberal, representada por las potencias Aliadas occidentales. Su rechazo se basaba en un supuesto cercenamiento de la soberanía. Su principal problema residía en ser un modelo foráneo, adoptado por los políticos locales, que actuaban mediante este "régimen" como agentes de intereses extranjeros.

Como se mencionaba con anterioridad, la Ley Sáenz Peña había representado una amenaza abriendo la puerta de ingreso a la arena política a un sector de la sociedad anteriormente vedado. La elección de Hipólito Yrigoyen a la presidencia en 1916, como su inmediata materialización, significaba para la oligarquía nacional un riesgo a la exclusividad de clase ya que, por medio del sufragio universal, había asumido al poder el primer presidente con una actitud democrática hacia las clases

\footnotetext{
33“Los agitadores comunistas no cejan en su afán de confundir la conciencia del pueblo". Ibídem, 14/6/1943, p. 4.

34Ídem.

35Ibídem.
} 


\title{
Laura Monacci
}

subalternas, tras una larga historia de presidentes conservadores que no habían trastocado la estabilidad social. El temor al poder de las masas -más aún si a éstas se las dejaba elegir- fue in crescendo hasta que el primer golpe militar sufrido en Argentina en septiembre de 1930 habría devuelto el orden que la democracia electoral había trastocado.

Para los nacionalistas afines a Osés, que daban a su discurso un tono de inclusión popular, la Ley Sáenz Peña resultaba una burla a la soberanía del pueblo argentino, quien no tendría voz propia para expresarse por medio del sistema electoral. Esto respondería a una creencia por parte de estos grupos de que las masas eran incapaces de participar en política, que mejor sería que fueran dirigidas por un verdadero patriota, o grupo de patriotas, que interpretara su voluntad y velara por sus necesidades. La participación popular directa en política era ampliamente temida, fuera tanto por la vía electoral, encarnada por Estados Unidos o Inglaterra, como por la vía revolucionaria, encarnada por la URSS.

Los jóvenes representantes de ambos sectores (comunistas y demócratas) son incluidos en un mismo grupo -representando un peligro aún mayor por su capacidad para complotar conjuntamente- en la siguiente cita ejemplificadora:

\begin{abstract}
"La camarilla judeo comunista de Villa María ataca la neutralidad del país" ...Llegaron el domingo último, otros de la comparsa entregadora, un ingeniero con ínfulas de tribuno demócrata, Cabrera Molina; un tal Reartes de la pandilla socialista; un personaje imberbe que afirmó hablar en nombre del Congreso de la Juventud Radical, un comunista, etc., los que se unieron con elementos de Argentine Action ${ }^{36}$ de esta ciudad. La gente sensata, la juventud valiente de Villa María, los obreros honestos, miraron con desprecio y con indignación la realización del acto que se empeñaron en consagrar los agentes asalariados de los Soviets rusos en combinación con los democráticos de toda laya que merodean en esta ciudad ${ }^{37}$.
\end{abstract}

Esta última cita ilustra la tensión existente entre diferentes grupos de jóvenes, aquellos que encarnaban la "antipatria" y aquellos "sensatos", "valientes" y "honestos" que desconfiaban de tales discursos. Este contrapunto ideológico, maniqueo, se presenta como una constante desde las páginas de estos diarios. Nos permite ver además, a diferencia de las otras citas presentadas más arriba, que no todos los jóvenes son considerados títeres, maleables, vulnerables a ser influenciados por el entorno desestabilizante, sino que hay un sector de ellos, los jóvenes nacionalistas, que representan una esperanza a futuro gracias a la firmeza de sus convicciones.

\footnotetext{
${ }^{36}$ Esta es la manera en que se menciona a "Acción Argentina" desde las páginas de El Pampero. Esta agrupación antifascista intentaba promover el apoyo de Argentina a los Aliados durante la Segunda Guerra. La irónica cita del nombre en inglés respondería a dicha orientación aliadófila. "Acción Argentina" fue disuelta en 1943 por el gobierno de facto de Ramírez. Para una profundización sobre "Acción Argentina" ver: Andrés Bisso. Acción Argentina: un antifascismo nacional en tiempos de Guerra Nacional: Acción Argentina y las estrategias de movilización del antifascismo liberal-socialista en torno a la Segunda Guerra Mundial (1940-1946). Buenos Aires, Prometeo libros, 2005.

37"La Camarilla Judeo Comunista de Villa María Ataca la Neutralidad del país". El Pampero, Bs. As., 8/12/1941, p. 7 .
} 


\section{La juventud argentina durante la Segunda Guerra Mundial. Una mirada desde periódicos nacionalistas}

Sin embargo, más allá del peligro que los grupos de jóvenes no nacionalistas pudiesen representar, se reconoce en estas páginas la activa participación en política de la juventud a través de los movimientos que representan. En este sentido, podemos ver cómo los jóvenes eran interpretados como un actor autónomo, cuya singularidad no era posible negar, por más que -según veremos en la siguiente citalos partidos tradicionales liberales sí lo intentaban hacer:

Una de las causas de la prematura decrepitud del radicalismo, según ha apuntado alguno de los más prestigiosos dirigentes de ese partido, consiste en la forma sistemática en que el partido cerró sus cuadros a la Juventud. El radicalismo se abroqueló detrás de los hombres que se atribuyen falsamente la dirección de la revolución del 90 y no dejó entrar en sus filas a nadie, sino a condición de aceptar integralmente sus puntos de vista y no discutirlos. La juventud pues, fue excluida del partido. No faltaron, sin embargo, iniciativas en el sentido de darle cabida. Una y otra vez, de tarde en tarde, la juventud partidaria trató de abrirse camino deseosa de gravitar en la marcha del partido a que había entregado su entusiasmo. Pero, invariablemente, en cada una de esas oportunidades los políticos que tenían en sus manos los puestos de mando se negaron categóricamente a abrir las filas, empezando por el Dr. Alvear, quien no disimuló jamás la profunda antipatía que experimentaba hacia los dirigentes juveniles ${ }^{38}$.

Además de la crítica abierta al partido y a uno de sus principales referentes, como era Marcelo T. de Alvear, la nota pone en relieve el vacío referencial y de participación política en que son dejados los jóvenes que intentaban iniciarse en sus filas. Esto vendría a resaltar la divergencia metodológica del movimiento nacionalista en relación a la juventud, destacando la relevancia que se le brindaba como actor protagónico dentro de sus filas. En lo que sigue de la nota queda en manifiesto una vez más la inviabilidad que para ellos representaba la política partidaria democrática, de la cual se hacía mención más arriba:

Aunque el asunto no interesó más que fuera de las filas del partido radical, hemos considerado interesante dar a conocer estos pormenores. Ellos revelan, por si hiciera falta más pruebas, la matemática imposibilidad de llevar a la práctica ningún intento serio u honesto dentro del ambiente político. Y esto explica el aparente absurdo de que en la primera convención de la "juventud radical" se haya intercalado en la lista de oradores al diputado socialista Pérez Leirós, junto con varios conocidos militantes comunistas o comunizantes. La política destruye fatalmente todo cuanto se pone a su alcance. El resultado del intento para organizar por primera vez la juventud radical lo demuestra irrefutablemente 39.

En este sentido, no se condena la participación política de los jóvenes en sí. Se cuestiona al partido radical en tanto representante de las instituciones liberales: "la política destruye fatalmente todo cuanto se pone a su alcance" y se promueve la participación de los jóvenes en movimientos por fuera de este circuito, como de

38 "El absurdo de la juventud radical". Ibídem, 26/4/1943, p. 8.

39'́dem. 


\section{Laura Monacci}

hecho sucedió con la proliferación de agrupaciones juveniles a lo largo de todo el periodo de entreguerras, entre las que destacaban: Alianza de la Juventud Nacionalista (AJN) (entre 30.000 y 50.000 miembros) ${ }^{40}$; Unión Nacional de Estudiantes Secundarios; Comité de la Juventud Argentina; Federación Juvenil Social Argentina; Federación Obrera Argentina; etc. ${ }^{41}$.

Otro aspecto característico de los nacionalistas criollos, era la defensa y promulgación de la fe cristiana, otorgando a la Iglesia Católica un rol de agente disciplinador y formador de valores, fundamental en la cosmovisión nacionalista. En este sentido, la militancia de los jóvenes, de las nuevas generaciones, renovando los votos de fe, comprometiéndose a llevar la palabra de Dios, resultaba otro de los puntos centrales para contraponer el buen ejemplo que encarnaban frente a aquellos jóvenes que representaban valores contrarios (constituyéndose, por lo tanto, en una amenaza). La siguiente cita celebra y da cuenta de su accionar:

"La juventud católica rindió hoy su homenaje de adhesión al Santo Padre": ... tuvo lugar esta mañana en la Iglesia Catedral una misa de Comunión General organizada por el Consejo Arquidiocesano de la Asociación de Jóvenes de la Acción Católica Argentina... Asimismo, la Junta de Gobierno de los Círculos Católicos de Obreros ha resuelto realizar el martes a las 9 una misa de Comunión General... Las Vanguardias Obreras Católicas, rama juvenil de la entidad, efectuará el mismo día a las 21 horas en la Iglesia Mater Consolationis, Cánning 1073, una solemne Hora Santa, la que estará a cargo del P. Rodolfo Carbonit2.

Para el nacionalismo argentino ambas instituciones, Iglesia y Ejército, se alzaban como pilares del orden social y espiritual. En los jóvenes que participaban de ellas se depositaban las esperanzas a futuro en que se construirían las nuevas bases de la moral nacional. La imagen de estos jóvenes estaba ligada, a su vez, a una exaltación del cuerpo atlético y saludable -propia de esta época, (tal como lo podemos ver especialmente en los afiches de propaganda de las juventudes hitlerianas)-, al desarrollo colectivo, y al espíritu de camaradería que el deporte y la actividad física despertarían en los jóvenes. Así es que con motivo de una competencia en el club River Plate por el día de la Educación Física se destaca: "El cuadro magnífico de la concentración realizada en River Plate alcanzó su máxima intensidad, al paso de la juventud de la Patria”, y en el copete: "Exaltación ferviente del valor de la cultura física"43.

La búsqueda de la perfección física mediante el esfuerzo y el trabajo iba de la mano del heroísmo que implicaba la destreza en el campo de batalla. Quienes desarrollaran habilidades físicas se presuponían buenos soldados. Para los nacionalistas, que veían en el Ejército un garante del orden social, cumplir estos

\footnotetext{
40Daniel Lvovich. Nacionalismo y antisemitismo en la Argentina..., Op. Cit, p. 296.

${ }^{41}$ Ronald Newton. El cuarto lado..., Op. Cit, p. 169.

42“La juventud católica rindió hoy su homenaje de adhesión al Santo Padre”. Ibídem, 27/6/1943, p. 7.

43“El cuadro magnífico de la concentración realizada en River Plate alcanzó su máxima intensidad, al paso de la juventud de la Patria”. Ídem, 29/10/1944, p. 4.
} 


\section{La juventud argentina durante la Segunda Guerra Mundial. Una mirada desde periódicos nacionalistas}

requisitos resultaba fundamental. En el contexto del levantamiento militar contra Castillo, que puso en el gobierno a Rawson (por 3 días) y continuó con Ramírez hasta febrero de 1944, se destaca el heroísmo de los jóvenes militares que dejaron su vida por la defensa de los valores nacionales que encarnaba tal "gesta patriótica":

"Juventud de la Argentina": Los 19 mártires descansan frente a su pueblo. Su gesto -renovada expresión del valor marcial de la juventud argentina-se repite en la conmovida expresión de los camaradas que les rinden honores y los depositan en el camposanto, para veneración y ejemplo de las generaciones, y para testimonio de la generosidad de la joven Argentina ${ }^{44}$.

Estas líneas nos ilustran un aspecto central que irá cobrando forma a lo largo del tiempo y a medida que el entonces Coronel Perón iba ganando mayor popularidad desde sus funciones en el gobierno de facto de Farrel: la idea de la juventud como depositaria del futuro nacional:

"Una Argentina sin fraudes, sin sofismas políticos, debe levantar la juventud, dijo el coronel Perón"... Rindo, señores, el homenaje de gobernante y de argentina [sic] a esta multitud que se agrupa en esta plaza 4 de junio. Ella representa la trilogía más hermosa de la patria: el pueblo, que representa la garantía de su grandeza; el ejército que representa la garantía de su soberanía y la juventud, que es el porvenir mismo de la patria... Necesitamos renovar valores. Esta revolución debe ser tomada por la juventud argentina y ésta debe llevarla adelante para estructurar una nueva Argentina, que sea más justa, más libre, y de la que estén ausentes el fraude, la mentira y los sofismas políticos. Anhelamos en primer término entregar a la juventud de [sic] país un trabajo casi completo, para que ella consiga afirmarlo y refirmarlo en el porvenir ${ }^{45}$.

La idea de revolución está presente en este discurso ligada a la defensa de los valores nacionalistas. En ese sentido nos remite a la "revolución del alma" encarnada por los fascistas, a la que hace referencia Paxton, que no pone en riesgo las bases materiales de la estructura social, sino que apunta a sentar las bases de una nueva sociedad cimentada en nuevos valores ${ }^{46}$. Ellos están basados a su vez en la grandeza de la creciente nación fundada en el trabajo de los jóvenes, actores fundamentales en la producción y reproducción de la economía nacional. Así, en El Pampero vemos esta nota destacando la labor de los jóvenes alemanes para los esfuerzos de guerra y el desarrollo y sostenimiento del nacionalsocialismo:

Berlín, 5 (T.O.). "Seis millones de jóvenes alemanes de ambos sexos están trabajando en las empresas del Reich", hizo constar el jefe de la Juventud Hitlerista, Arthur Axmann, en un discurso que pronunciara ante obreros y obreras jóvenes de una gran empresa berlinesa...

\footnotetext{
44"Juventud de la Argentina". Ibídem, 6/6/1943, p. 7.

45 "Una Argentina sin fraudes, sin sofismas políticos, debe levantar la juventud, dijo el coronel Perón”. El Federal, Bs. As., 29/10/1944, p. 2.

46Robert Paxton. Anatomía del fascismo..., Op. Cit, p.166.
} 


\section{Laura Monacci}

"Estos productores -dijo Axmann- contribuyen con su trabajo a la producción de armamentos alemanes. La juventud productora de la Gran Alemania comprende con instinto seguro que el objetivo de esta guerra es la realización de una organización justa socialista. Los jefes de la juventud hitlerista consideran uno de sus más importantes deberes la tutela de los miembros productores de la juventud nacionalsocialista ${ }^{47}$.

Tanto los nacionalistas reunidos en torno a Osés como el nacionalsocialismo veían en los jóvenes al actor revolucionario por excelencia, de la mano de otros dos pilares: el pueblo y el Ejército. En Argentina, el futuro gobierno de Perón desarrollará programas de actividades educativas para la juventud, como también brindará una mayor participación en la organización política partidaria desde la cual los jóvenes cobrarán aún mayor protagonismo y visibilización.

\section{Conclusión}

A la hora de dar comienzo a este trabajo surgieron varios interrogantes conceptuales en torno a qué lecturas hacer acerca del grupo de jóvenes, objeto de estudio ¿Podemos hablar de un actor social autónomo? ¿Eran parte de un colectivo social mayor que los incluía? ¿Estaban en tensión con otros grupos etarios a partir de su acción y compromiso político? ¿Creció su participación y visibilización a lo largo del periodo analizado? Consideramos que lo expuesto anteriormente nos permite dar una respuesta afirmativa a estas preguntas en relación a cómo estaba constituido el tejido social e ideológico argentino durante la Segunda Guerra Mundial. No son en estos diarios reconocidos solamente los jóvenes nacionalistas, sino que se destacan en su confrontación con otras agrupaciones juveniles ubicadas en las antípodas ideológicas. La vinculación de las noticias locales e internacionales con el accionar de los jóvenes que componen cada movimiento da cuenta de su reconocimiento como actor político autónomo y de su creciente participación en la agenda política, social y cultural. Esto está ligado a la entidad que se les otorgaba como garantes del futuro nacional. En los jóvenes se depositaban muchas veces las esperanzas y los peores fantasmas en proyección al devenir político, económico, pero fundamentalmente moral de la nación. De la misma manera que se fomentaban las actividades de los jóvenes patriotas en tanto futuros dirigentes y ciudadanos adultos responsables, de igual manera se temía a aquellos que podían poner a la soberanía y a los valores nacionalistas en riesgo oficiando de agentes del enemigo ideológico foráneo e interno.

Un aspecto central a destacar a modo de conclusión es que siempre que hablamos de los jóvenes nacionalistas lo hacemos refiriéndonos a jóvenes varones. No se hace mención en estas páginas a la participación política de las mujeres en estas filas. Las mujeres nacionalistas ocupan el rol doméstico esperable

47 "Seis millones de jóvenes alemanes trabajan en la industria germana”. El Pampero, Bs. As., $5 / 5 / 1943$, p. 3 


\title{
La juventud argentina durante la Segunda Guerra Mundial. Una mirada desde periódicos nacionalistas
}

correspondiente al género, acompañando a sus hombres en cenas de camaradería o cumpliendo funciones de benefactoras sociales, pero son los hombres quienes ocupan y deciden en el ámbito público político.

Sin embargo, sí se critica en estos diarios, y se hace referencia, a las mujeres que participan de otros movimientos o agrupaciones, como se lee a continuación:

\begin{abstract}
"La policía apaleó a las mujeres"-dice un diario importante, complicándose en la maniobra judía, que consiste en mandar rebecas y raqueles miopes y pelirrojas a las manifestaciones. El uso de las muchachas judías para esos encontrones permite luego dar una nota sentimental y engañar al público con la falsa información de la tradicional galantería criolla, eclipsada por la acción de los policías ${ }^{48}$.
\end{abstract}

Esta cita condensa no sólo el ferviente antisemitismo que los nacionalistas explayaban diariamente en sus páginas, sino el desprecio hacia la acción política de las mujeres, negando en la participación de las mismas la posibilidad de un compromiso político personal y colectivo de lucha. En estas breves líneas su presencia en las manifestaciones responde a un "uso" que se está haciendo de ellas, que son "mandadas" para "dar una nota sentimental” y "engañar al público". Tanto el antisemitismo nacionalista como el rol de las mujeres en estas páginas son temas que, por su importancia, deberán ser desarrollados en extenso, pero que exceden nuestro actual trabajo.

\section{Bibliografía}

Andrés Bisso. Acción Argentina: un antifascismo nacional en tiempos de Guerra Nacional: Acción Argentina y las estrategias de movilización del antifascismo liberalsocialista en torno a la Segunda Guerra Mundial (1940-1946). Buenos Aires, Prometeo libros, 2005.

Carles Feixa. De jóvenes, bandas y tribus. Antropología de la juventud. Barcelona, Ariel, 1998.

Daniel Lvovich. Nacionalismo y antisemitismo en la Argentina. Buenos Aires, ediciones B Argentina S.A., 2003.

Daniel Muchnik. El rechazo mundial a los judíos. Buenos Aires, Ariel, 2014.

Daniel Muchnik. Negocios son negocios. Los empresarios que financiaron el ascenso de Hitler al poder. Buenos Aires, Edhasa, 2008.

48 “Los judíos en la calle”. Ídem., 9/12/1941, p. 9 


\section{Laura Monacci}

Diario El Federal, Buenos Aires, Archivo en BIBHUMA, Depósito Cerrado, DHU 1122, La Plata, Argentina, 1944.

Diario El Pampero, Buenos Aires, Archivo en BIBHUMA, Depósito Cerrado, DHU 1119, La Plata, Argentina, 1941-44.

Eric Hobsbawm. Historia del siglo XX. Buenos Aires, Crítica, 2003.

Fernanda Cortés Navarro y Carlos Reina Rodríguez. Historia, juventudes y política: de la Escuela Republicana del siglo XIX a las élites y juventudes políticas en los gobiernos del siglo XX en Colombia. Bogotá, ed. UD, 2014.

François Furet. El pasado de una ilusión. Ensayo sobre la idea comunista en el siglo XX. Madrid, FCE, 1996.

Ian Kershaw. "Nazisme et stalinisme. Limites d'une comparaison". Le Débat, Vol. II, № 89, París, marzo-abril 1996, pp. 177-189.

Josep Fontana. Introducción al estudio de la historia. Barcelona, Crítica, 1999.

Ma. Dolores Béjar. Historia del siglo XX; Europa, América, África y Oceanía. Buenos Aires, Siglo XXI, 2011.

Orlando Figes. Los que susurran. La represión en la Rusia de Stalin. Buenos Aires, Edhasa, 2009.

Robert Paxton. Anatomía del fascismo. Barcelona, Península, 2004.

Ronald Newton. El cuarto lado del triángulo. La "amenaza nazi" en la Argentina (1931-1947). Buenos Aires, Ed. Sudamericana, 1995.

Sandra Souto Kustrín. “Introducción: juventud e historia”. Hispania. Revista española de Historia. Vol. LXVII, № 225, Madrid, enero-abril 2007.

Sergio Pujol. La década rebelde. Buenos Aires, ed. Emecé, 2002.

Recibido: $12 / 12 / 2017$

Evaluado: 05/01/2017

Versión Final: 25/01/2018 